\title{
Use of Structural Equation Modeling Techniques to Overcome the Empirical Issues Associated With Quantification of Attitudes and Perceptions
}

\author{
U. K. Jayasinghe-Mudalige, J. M. M. Udugama and S. M. M. Ikram \\ Dept. of Agribusiness Management, Faculty of Agriculture and Plantation Mgt., \\ Wayamba University of Sri Lanka, Makandura, Gonawila (NWP), Sri Lanka \\ (Corresponding author: udith@hotmail.com)
}

\begin{abstract}
The social scientists work on economic problems associated with attitudes and perceptions of respondents to a survey on a given issue naturally face several challenges with regard to quantification of which to develop estimable variables to be used in further analyses. This article explores, using the special case of economic incentives for Sri Lankan agri-food processing firms to adopt enhanced solid waste management practices in the firm, the outcome of statistical methods employed to overcome such empirical issues, including: (a) "Mutual Exclusivity" and "Endogeneity" of incentives, i.e. prevalence of an individual incentive as an element of a system; (b) "Subjectivity", i.e. the management of firm perceives unpredictably on these incentives in terms of potential benefits and costs to the firm, and (c) "Unobservability", i.e. the management cannot directly observe the nature of incentives prevailing at the firm level. It uses the Structural Equation Modeling techniques with the aid of Analysis of Moment Structures (AMOS) statistical package to overcome these issues, where a family of statistical models that seek to explain the relationships among multiple variables were formulated by combining a Measurement Model [commonly referred to as Confirmatory Factor Analysis (CFA)] with Structural Model into a simultaneous statistical test. The outcome of analysis, which used data collected from 325 firms by means of a questionnaire-based survey comprising of 9 Constructs/latent variables (i.e. incentives considered in the analysis) and 51 Indicators (attitudinal statements), facilitate deriving an Incentive Index for each incentive reflecting its relative strength at the level of firm, and in turn, to use as explanatory variables in modeling.
\end{abstract}

Keywords: Confirmatory Factor Analysis, Economic incentives, Reliability analysis, Structural Equation Models, Subjectivism, Unobservability, Validity

\section{Introduction}

The social scientists work on economic problems associated with attitudes and perceptions of respondents to a survey on a given issue naturally face several 
challenges with regard to quantification of which to develop estimable variables to be used in further analyses. This article presents the outcome of a two stage empirical analysis that used a statistical methodology based on Structural Equation Modeling (SEM) to overcome such challenges. Here we survey the special case of the Ministry of Environment's initiative to promote the adoption of Solid Waste Management Practices (SWMPs) for the firms belonging to agrifood processing sector in Sri Lanka. This article, in particular, discusses the use of SEM to develop "estimable variables" for individual economic incentives faced by a firm to act on these practices, which can, in turn, be included in multivariate models as explanatory variables reflecting the real strength and impact of each incentive.

SEM provides a useful way in which to determine whether observed data concur with a priori hypotheses on the structure of incentives (Hughes et al., 1986; Joreskog and Sorbom, 2001). It has the advantage of providing a method for dealing with multiple and inter-related dependence relationships, while providing statistical efficiency and to assess directly unobservable concepts for which respondents possess subjective assessments in terms of a number of observable components (Hair et al., 1998). Indeed, SEM has been used in previous empirical studies of consumer and managerial behavior (see, for example Henson and Traill, 2000; Nakamura et al., 2001) with great success.

\subsection{Case for Analysis: Incentives for a Food Processing Firm to Adopt SWMPs}

The Ministry of Environment under its "National Strategy for Solid Waste Management" has introduced a number of specific procedures that firms in the food processing sector should adopt in order to mange the solid waste generated in a firm. These include: (1) "Sorting of waste based on 3R System" Establishment of necessary infrastructure facilities in appropriate places and allocating labor for the purpose; (2) "Composting" - The conversion of solid waste materials into composts, in which the heavy metal composition should be maintained below the recommended standards; (3) "Biogas technology" Establishing units in accordance with the guidelines provided by the Ministry; (4) "Biodegradable packaging materials" - Using material such as paper, glass, cloth, etc. instead of polyethylene and other non-biodegradable plastics. In case the use of plastic is unavoidable due to the nature of the industry, it must be degradable plastics; (5) "Sanitary land filling" - The maintenance of a site for which the firm should obtain clearance from the State after going through the Initial Environmental Examination (IEE) followed by Environmental Impact Assessment (EIA) based on guidelines provided by the Central Environmental Authority (CEA) in Sri Lanka. Moreover, the Ministry encourages initiatives by individual firms to manage waste. Firms can obtain guidelines, proper training, and certification to adopt environmentally sound practices: (6) a set of "Good 
Manufacturing Practices" (GMP); (7) Regular Waste Auditing system and (8) ISO 14000 Environmental Management System, etc. through the Sri Lanka Standards Institution (SLSI).

We can conceptualize that there are three social processes, namely: (1) market; (2) political and (3) judicial can have important and distinct functions with respect to activities in the firm towards implementing environmental management controls (Figure 01). The market processes, for example, may contribute in this respect by coordinating the human action of firms through voluntary cooperation. In the case of environmental quality, numerous types of environmental management controls, for example ISO 14000 series of standards and enterprise-oriented and customer-specific practices, may be adopted by food processing firms voluntarily, or sometimes on the recommendation of trade and/or industry organizations that are working collectively for the betterment of the industry, i.e. 'quasi- voluntary' (Caswell et al., 1998). The political process contributes by formulating and coordinating legitimized forces. In Sri Lanka, those public statutory and regulatory requirements of the National, Provincial and Municipal governments satisfy this requirement. Along with these, the judicial process contributes through dispute mediation, in which both the government and private institutions (non-governmental) play a substantial role. However, each of these institutions may also be subject to pathologies of their own in terms of market failure, policy failure, and failures in the judicial system. It is not possible for these social processes to work perfectly. Further, it would not be possible to recognize a system in which they did work perfectly.

\subsection{Development of Estimable variables to represent Individual Incentives in the Model}

We can state that the degree of responsiveness of a firm towards the environment is reflected by the types of levels of environmental management controls and practices $\left(\mathrm{SWMP}_{i}\right)$ adopted by the firm $i$, which depend on the individual incentives faced by the decision maker/management in this respect $\left(\mathrm{I}_{\mathrm{ji}}\right)$, where $j=$ types of incentives $(j=1,2,3 \ldots \mathrm{m})$. The relative strength of an individual incentive $(j)$ on this behavior can have a relationship with characteristics of the firm $\left(\mathrm{F}_{\mathrm{ki}}\right)$, where $k=$ size and type of the firm, etc. (Nakamura et al., 2001).

For the purpose of this study, we selected a set of 9 individual incentives that embody the characteristics of market-based incentives such as (1) cost/financial implications (CST), (2) technical efficiency (TCE) (3) human resource efficiency (HRE), (4) sales \& revenue (SLR), (5) commercial pressure (CPR) and (6) reputation (REP). We also selected regulatory incentives such as (7) existing government regulation (EGR) and (8) anticipated government regulations (AGR) and the liability incentive, that is, (9) liability laws (LBL) 
(Caswell et al., 1998; Jayasinghe-Mudalige and Henson, 2007a; 2006b; Segerson, 1999).

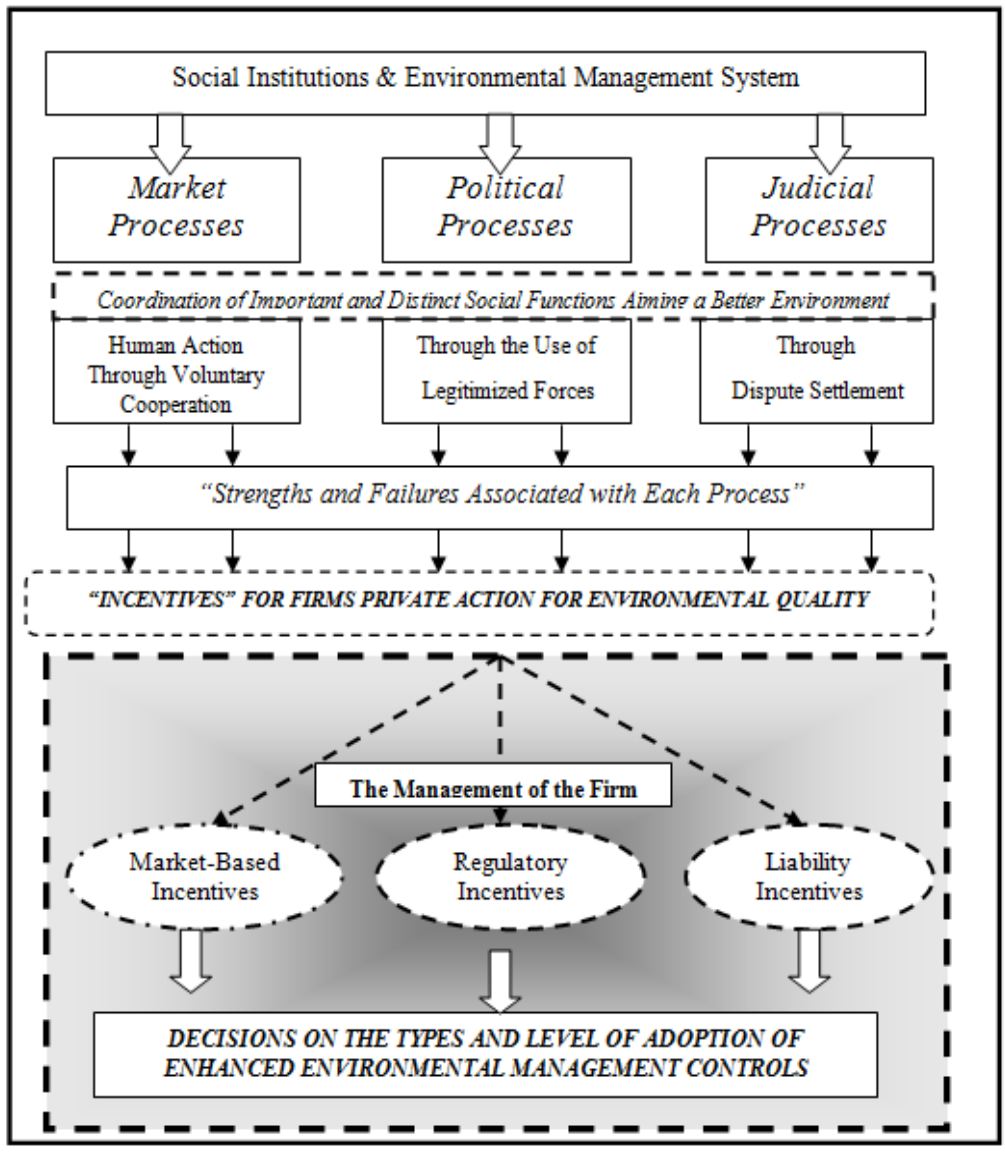

Figure 1: Conceptual Framework

The relationship between the SWMP adopted and the economic incentives can, therefore, be expressed using the following econometric model:

$$
\begin{aligned}
\operatorname{SWMP}_{i}=\sigma_{0}+ & \beta_{1} * \mathrm{CST}_{\mathrm{i}}+\beta_{2} * \mathrm{TCE}_{\mathrm{i}}+\beta_{3} * \mathrm{HRE}_{\mathrm{i}}+\beta_{4} * \mathrm{SLR}_{\mathrm{i}}+\beta_{5} \\
& * \mathrm{CPR}_{\mathrm{i}}+\beta_{6} * \mathrm{REP}_{\mathrm{i}}+\beta_{7} * \mathrm{EGR}_{\mathrm{i}}+\beta_{8} * \mathrm{AGR}_{\mathrm{i}}+\beta_{9} \\
& * \mathrm{LBL}_{\mathrm{i}}+\gamma_{1} * \mathrm{FT}_{\mathrm{i}}+\gamma_{2} * \mathrm{FS}_{\mathrm{i}}+\gamma_{3} * \mathrm{VT}_{\mathrm{i}}+\gamma_{4} * \mathrm{EX}_{\mathrm{i}}+\varepsilon_{\mathrm{I}}
\end{aligned}
$$

where: $\mathrm{SWMP}_{i}$ denotes the dependent variable (i.e., solid waste management practices adopted by a firm). The right hand side variables include: $\sigma_{0}=$ intercept, $\beta_{j}=$ coefficients of 9 individual incentives $(j=1,2 \ldots 9)$ considered in 
the analysis, and $\gamma_{\mathrm{k}}=$ coefficients of characteristics of a firm $\left(\mathrm{F}_{\mathrm{ki}}\right)$ such that $F T=$ firm type; $F S=$ firm size (based on annual returns); $V T=$ Vintage, and $E X=$ Export orientation.

Though the incentives identified above ( $j=1$ to 9$)$ can have a significant impact, either positively or negatively, on a performance of a firm with regard to adoption of the SWMPs recommended by the Ministry; we were, however, unable to include each incentive directly into the econometric model specified as its explanatory variables. The reasons for this were:

(a) Mutual Exclusivity and Endogeneity - the prevalence of an individual incentive as an element of the system (Nakamura et al., 2001; Shavell, 1987);

(b) Subjectivity - the management of the firm perceives these incentives in terms of potential benefits and costs to the firm (Buchanan, 1969); and

(c) Unobservability - the management cannot directly observe the nature of the incentives prevailing at the firm level (Hair et al., 1998).

These reasons highlight the importance of developing estimable variables to represent the true strength of each incentive prevail at the level of the firm. In order to overcome these difficulties and to develop such variables, we have decided to use the Confirmatory Factor Analysis (CFA) techniques [i.e., a multivariate data analysis technique that comes under Structural Equation Modeling (SEM)] for the 9 individual incentives $(j=1,2 \ldots 9)$, which we have summarized below.

SEM is a family of statistical models that seeks to explain the relationships among multiple variables and combines features of two models: (i) Measurement Model [Confirmatory Factor Analysis (CFA)], and (ii) Structural Model into a simultaneous statistical test (Hair et al., 1998; Hughes et al., 1986). . It has the ability to incorporate latent variables (i.e. a hypothesized and unobserved concept such as "incentives" considered in this analysis) that can only be approximated by observable or measured variables or indicators into the analysis (Hair et al., 1998; Hoe, 2008). The CFA helps analysts to hypothesize the behavior of a firm in terms of these incentives and, in turn, to determine whether the observed data on each incentive confirmed the hypothesized behavior. We used the CFA part of a SEM - commonly described as the measurement model (MM) - in this study essentially to objectively assess and develop estimable variables for individual incentives, which specifies a series of relationships that suggests how 'measured variables' represent a Latent Construct. MM is, essentially, a sub-model in SEM that: (i) specifies the Indicators for each Construct, and (ii) assesses the reliability of each Construct for estimating the causal relationships. It is similar in form to Factor Analysis; however, the major difference lies in the degree of control provided the 
researcher. In the MM the researcher specifies which variables are Indicators of each Construct, with variables having no loadings other than those on its specified Construct. However, in Factor Analysis, the researcher can specify only the number of factors although all variables have loadings for each factor.

Constructs (latent variables) are concepts that the researcher can define in conceptual terms but cannot be directly measured (for e.g., the respondent cannot articulate a single response that will totally and perfectly provide a measure of the concept), or measured without error. Constructs are the basis for forming causal relationships, as they are the 'purest' possible representation of a concept. A construct can be defined in varying degrees of specificity ranging from quite narrow concepts (for e.g., household income) to more complex or abstract concepts (intelligence or emotions). Yet, no matter what its level of specificity is, a Construct cannot be measured directly and perfectly, but must be approximately measured by items/Indicators. The measured variables of a Construct included in the MM are commonly referred to as Indicators in the literature that reflects exactly the observable characteristics of the firm with respect to the Construct that underlines it. In other words, Indicators are 'observed values' that is used as a measure of the concept or Construct that cannot be measured directly. The researcher must specify which Indicators are associated with each Construct. In this study, the nine individual incentives are such latent variables and are defined as Latent Constructs of the MM. In turn, we specify a set of 'attitudinal statements' reflecting observable characteristics of these incentives as the Indicators of the model (see below). Customarily, researchers use firsthand information gathered from participants to the study (e.g., owners/managers of food processing firms in this particular case) in order to develop the attitudinal statements (i.e., Indicators of the Constructs) (Zechmeister et al., 2009; Zikmund, 2003).

Using the standard notations (Jöreskog \& Sörbom, 2001; Hair et al., 1998), we can represent any single Indicator associated with an exogenous Latent Construct in the MM thus as a series of equations in the form of:

$$
\mathrm{x}_{1}=\lambda_{\mathrm{x} 1,1} \xi_{1}+\delta_{1}
$$

where, $\lambda_{x l, 1}$ represents the relationship between the latent factor $\xi_{1}$ and the measured variable, $x_{l}$, that it explains. But since it does not explain this relationship perfectly, $\delta_{l}$ represents the error.

Once we have identified the Constructs and their corresponding Indicators, we can use the Analysis of Moment Structures (AMOS) [version 16] statistical software to construct the MM as shown in Figure 02. We use the scores provided by respondents to each Indicator on the multi-point likert-scale with the AMOS and the Statistical Package for Social Sciences (SPSS) [version 14] to get rid of the empirical issues cited above (i.e., non-exclusivity, endogeneity, subjectivity, unobservability, etc.) by applying a number of statistical tests specified under the 
CFA as follows. The recommendations of Hair et al., (2006) were considered to assess the validity of Measurement Model for its "Model Fit" and the "Construct Validity". The former was determined using Multiple Fit Indices. Construct Validity means the ability of Indicators of a Construct to accurately measure the concept under study. It concerns the theoretical relationship of a variable to other variables, and it is the extent to which a measure behaves in the way the Construct it is hypothesized to measure should behave with respect to established measures of other Constructs (De Vellis, 1991). A number of other measures were employed to assess the Construct Validity, including: (a) "Face Validity" (content and meaning of the attitudinal statements representing Indicators in relation to their associated incentives); (b) "Convergent Validity" (indicators of a specific incentive should converge or share a high proportion of variance in common); (c) "Discriminant Validity" (extent to which a incentive is truly distinct from other incentives) and, (d) "Nomological Validity" (whether the correlations among the incentives in the measurement theory made sense).

Convergent Validity was assessed by means of: (a) Factor Loadings (given as Regression Weights in the AMOS); (b) Reliability, and (c) Average Variance Extracted (AVE). With regard to Factor Loadings, Hair et al. (2006) recommend that Standardised Regression Weights obtained through the AMOS should be 0.5 or higher, ideally 0.7 or higher and at a minimum statistically significant. Construct/Scale Reliability measures whether a set of Indicators representing a Construct are consistent in their measurement and it is customary to use the Cronbach's alpha $(\alpha)$ (Cronbach, 1951) for this purpose. Since the aim of the test is to maximize $\alpha$, researchers generally accept values above 0.7 as demonstrating that a scale is internally consistent. It is, however, difficult to justify a proposed Indicator of a Construct in exploratory research if its reliability were less than 0.5 , because in that case more than 50 percent of its variance would be an error variance (Nunnally, 1978). In addition to Cronbach's alpha to test for Reliability, we have resolved to estimate the Construct Reliability (CR) using the Equation (3), as it is recommended to be used in conjunction with SEM for this purpose (Garver and entzer, 1999):

$$
\mathrm{CR}=\frac{\left(\Sigma \lambda_{\mathrm{j}}\right)^{2}}{\left[\left(\Sigma \lambda_{\mathrm{j}}\right)^{2}+\Sigma\left(1-\lambda_{\mathrm{j}}^{2}\right)\right]}
$$

where, $\lambda$ denotes the Standardized Factor Loading and $n$ shows the number of Indicators used in the model. The rule of thumb for CR is that it should be 0.6 or higher, and ideally 0.7 or higher to mean that reliability is good with internal consistency (Fornell and Bookstein, 1982).

Based on the same notations, AVE can be estimated using the expression in Equation (4) (Hair et al., 1998) and a value of 0.5 or higher to which suggests 
adequate convergence and that the scale has higher distinct validity (Fornell and Larker, 1981):

$$
\frac{\sum \lambda_{\mathrm{i}}^{2}}{\mathrm{n}}
$$

The recommended approach for establishing Discriminant Validity is to compare the squared correlation between two constructs with either of their individual AVE estimates (Hair et al., 1998). The AVE estimates should be greater than the squared correlation estimate. In addition to distinctiveness of constructs, Discriminant Validity also means that individual measured items should represent only one latent construct. The presence of cross-loadings indicates a Discriminant Validity problem. If high cross-

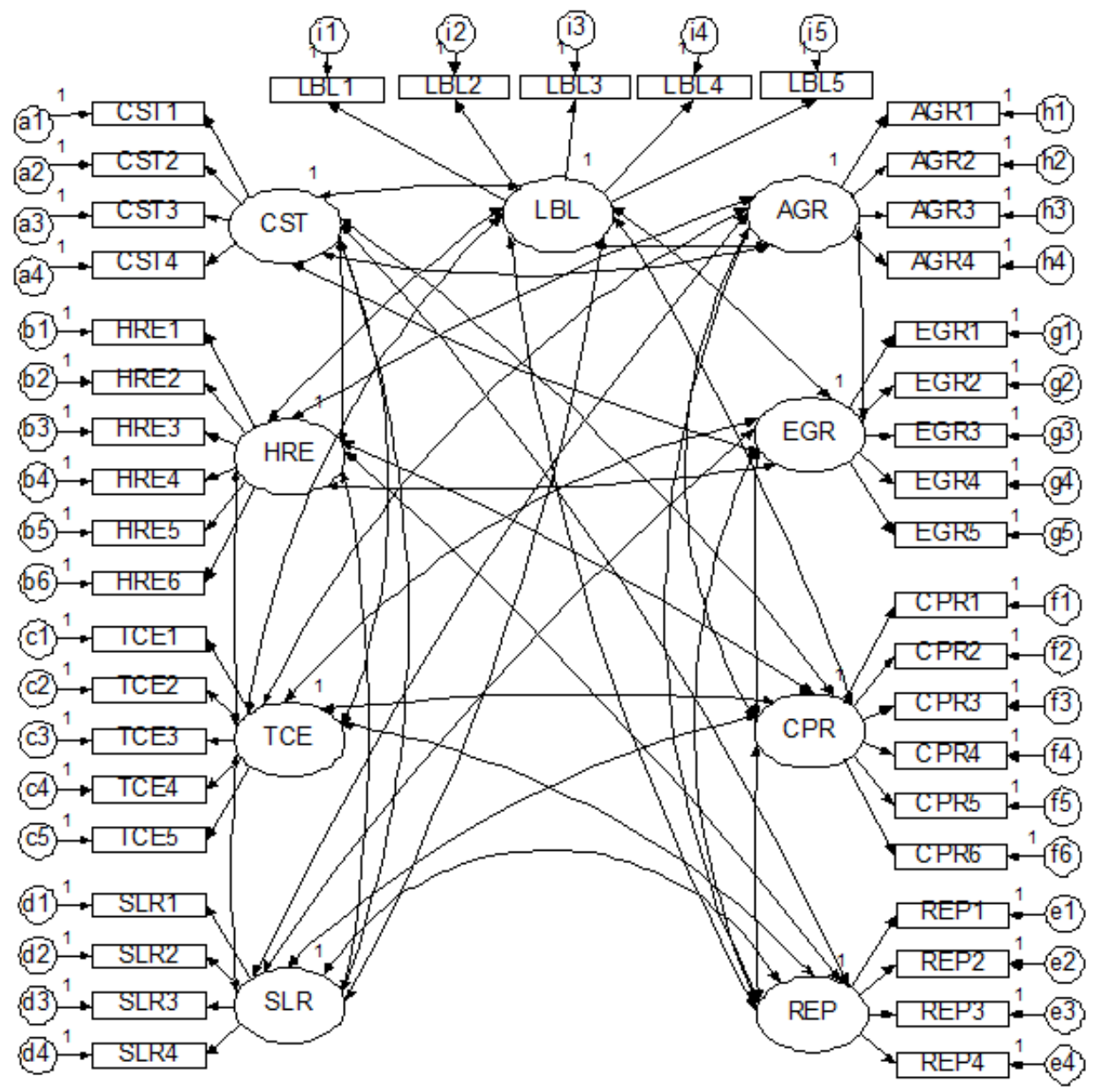

Figure 2: Measurement Model in SEM (Using AMOS) 
loadings do indeed exist, and they are not represented by the measurement model, the CFA fit should not be good (Hair et al., 1998).

Nomological Validity was tested by examining whether the correlations among the incentives in the measurement theory made sense. Face validity can be established early, i.e., during the development of the questionnaire and scales for assessment.

Researchers frequently use the Multi-Trait Multi-Method matrix (MTMM matrix), introduced by Campbell and Fiske (1959), to assess Construct and Discriminant Validity, which reports the correlation between different Constructs used in the analysis and an alternative measure used to evaluate the same phenomenon (e.g., Validation Items) (Henson and Traill, 2000). Although techniques deriving from the output given by the AMOS software succeed the MTMM matrix technique, we utilized it here both to compare the accuracy of the alternative AMOS-based techniques and for use during the Pilot Study. Following the standard guidelines for constructing a validation item for the CFA, we included 9 validation items in the questionnaire to represent corresponding individual incentives (constructs). Given two or more Constructs and two or more ways of measuring each, we can expect a high correlation between these two different measures when they are used to evaluate the same Construct, but a low correlation between these measures when used for different Constructs, or in statistical terms this satisfies the condition of Convergent Validity and Discriminant Validity (Campbell and Fiske, 1959). The two different measures we use in this analysis to develop the MTMM matrix include: (1) value of the Incentive Related Index and (2) Validation Items.

We may use the outcome of CFA obtained through AMOS and SPSS to determine whether the Indicators of Constructs included in the MM originally are statistically valid and reliable to derive an estimable variable for the corresponding incentive. If not, we need to purify the MM used in AMOS by removing those invalid and unreliable Indicators from respective Constructs and reiterate the above statistical tests on remaining Indicators until the conditions given under each test is satisfied. Once we choose the valid and reliable Indicators of each Construct through this process, we may regard the scores given by respondents to these indicators on the multi-point likert-scale as objective measurements or, in other words, free from those empirical issues listed elsewhere, and proceed with further analysis.

\subsection{Deriving the Incentive Index}

We next used the scores given by respondents [i.e., every firm included in the sample $(i=1,2 \ldots \mathrm{n})]$ to the Indicators of a Construct (i.e., attitudinal statements of an individual incentive) in order to derive an index for the respective incentive $(j=1,2 \ldots 9)$ - referred to here as Incentive Index $\left(\mathrm{I}_{j i}\right)$ - by taking the 
aggregate of the scores given by a respondent to all Indicators of an incentive on the 5-point Likert Scale (AIS) and dividing it by the Maximum Potential Score (MPS) that can be obtained by the respective incentive as shown in Equation (5) below:

$$
\mathrm{I}_{\mathrm{ji}}=\frac{\text { Aggregate Score (AGS) }}{\text { Maximum Potential Score (MPS) }}
$$

We use MPS in equation (4) to normalize the value of the Incentive Index so that its value ranges from -1 (minimum) to 1 (maximum). In effect, the magnitude of the Incentive Index obtained for each incentive for every firm signals the perceptions and the true behavior of the firm in question in relation to these individual incentives, and we can use it as a proxy to represent those incentives in the econometric model (Henson and Traill, 2000).

\subsection{Data and Study Area}

According to the Department of Census \& Statistics - Industrial Survey (2003/2004), there were 36,939 food processing firms in nine provinces in Sri Lanka. We have resolved to select the food processing firms belonging to five key sub-sectors based on the type of product: (1) processed fruits and vegetables (PFV)]; (2) coconut products (COP); (3) essential oils (ESO); (4) non-alcoholic beverages $(\mathrm{NAB})$, and (5) other processed products (OPP), located in four provinces [i.e., Western (WP), North Western (NW), Central (CP) and Southern (SP)] for the collection of data. Within these provinces higher population densities are already aggravating the solid waste problem, and these provinces are responsible for $5,839(15.8 \%), 7,870(21.2 \%), 4,606(12.5 \%)$ and 4,717 $12.8 \%$ ) out of 36,939 food processing firms, respectively. For the purposes of preparing the sampling framework, we obtained the mailing lists of food processors by contacting reputed institutions such as: (a) the Department of Census \& Statistics of Sri Lanka; (b) the main and regional offices of the Export Development Board of Sri Lanka; (c) the Ministry of Industrial Development; (d) the Federation and Regional Chambers of Industry and Commerce; (e) National Agribusiness Council of Sri Lanka; (f) Coconut Research Institute of Sri Lanka; (g) Fruit and Vegetable Processors Association of Sri Lanka, and (h) Sri Lanka Standards Institution.

\section{Data Collection and Analysis}

The data collection and analysis were carried out in two phases, namely: (i) the Pilot Study, and (ii) the Main Survey. We provide the purpose of and activities in each phase briefly. 


\section{Phase I: Pilot Study}

The purpose of the Pilot Study was to validate the preliminary questionnaire, which we had designed with a specific format in order to collect information from the respondents to develop estimable variables for the individual incentives (through the CFA) in a straightforward fashion. The questionnaire comprised 81 attitudinal statements (i.e., 8 statements per incentive $\mathrm{x} 9$ incentives +9 validation items to represent 9 incentives).

We carried out a series of in-depth face-to-face interviews supported by the structured questionnaire with the top-most executives from 36 food processing firms belonging to the 5 sub-sectors listed above in order to collect data from July to September 2008. The interview was followed by an inspection of the site for cases where permission was granted. We asked each respondent first to rate his/her perception about the observable characteristic explained in each statement (i.e., Indicator) with respect to the current performance of his/her firm on a two-point Likert scale, i.e., (1) agree ("yes"), or (2) disagree ("no") having instructed the respondent to rate the same statement on a five-point Likert-scale by taking into account of the extent to which he/she agrees (if they say "yes" in the $1^{\text {st }}$ rating) or disagrees (if they say "no" in the $1^{\text {st }}$ rating) with this particular statement (Oppenheim, 1992).

Following the good practices cited in literature with regard to setting a set of Indicators of a Construct in a Measurement Model (Hair et al., 1998; Henson and Traill, 2000), these 81 statements were written in such a manner that a firm would "agree" ("disagree") with a statement [i.e., "Yes ("No")], in general, if the phenomenon underpinning it was forced and/or was perceived as a "positive" ("negative") incentive for that particular firm to "act" (or "not to act") on environmental quality.

We subjected the data from the 36 firms next to CFA techniques described above to eliminate superfluous Indicators and to select the most valid and reliable statements for the final questionnaire. The CFA techniques offered by the AMOS package was not utilized during the phase since the sample was not sufficient for analysis; for CFA using Maximum Likelihood Estimation (MLE) on AMOS, the minimum recommended sample size is 150 (Hair et al, 1998). Before commencing the CFA, we re-inverted the scores given to certain statements that were inverted purposely in the questionnaire. First, we carried out the Scale Reliability Test using the SPSS (Version 14). The analysis followed several rounds, and based on the values of Cronbach Alpha obtained, we excluded a number of statements from each incentive at the end of each round until we obtained its best value (see Table 1). Except for 3 incentives (i.e., TCE, SLR and LBL), the value of Cronbach Alpha was greater than the commonly accepted level of 0.7 . Nevertheless, we did not remove the remaining statements of these 3 incentives from the questionnaire as a slight deviation from the accepted value of 0.7 was possible due to specific reasons cited in the CFA 
literature such as, amongst the others: (i) the high degree of the heterogeneity of firms that responded to the statements; (ii) the relatively small number of responses assessed that may not be sufficient to increase the overall reliability amongst all statements $(\mathrm{n}=36)$, and (iii) considering the fact that the said values were above 0.67 (i.e., just -0.03 lower than the accepted value).

The performance of the Principle Axis Factoring on the scales for nine incentives next indicated a high level of Unidimensionality, with all statements except two that have loadings exceeding 0.35. Indeed, most statements had loadings exceeding 0.60 while no statements had factor loadings less than 0.30 . Therefore, none of the statements subjected to this test, which had already passed the Scale Reliability testing, was removed. At the end of these tests, we used the scores given by respondents to 43 out of 81 statements selected in order to derive the Incentive Index $\left(\mathrm{I}_{j i}\right)$ of corresponding incentives based on equation (4) using the Multi-Item Summated Scale (MISS) techniques.

Table 1: Summary of Statistics from CFA

\begin{tabular}{|l|c|c|c|c|c|c|}
\hline \multirow{2}{*}{$\begin{array}{c}\text { Incentive } \\
\text { (Construct) }\end{array}$} & $\begin{array}{c}\text { No. of } \\
\text { Indicators } \\
\text { Used }\end{array}$ & $\begin{array}{c}\text { Excluded } \\
\text { After CFA }\end{array}$ & $\begin{array}{c}\text { Selected for } \\
\text { Main } \\
\text { Survey }\end{array}$ & $\begin{array}{c}\text { Value of } \\
\text { Cronbach } \\
\text { Alpha }\end{array}$ & AVE & CR \\
\hline CST & 9 & 5 & 4 & 0.905 & 0.8716 & 0.9643 \\
\hline TCE & 9 & 4 & 5 & 0.677 & 0.8586 & 0.9680 \\
\hline HRE & 9 & 3 & 6 & 0.907 & 0.6641 & 0.9220 \\
\hline SLR & 9 & 5 & 4 & 0.605 & 0.4609 & 0.8338 \\
\hline REP & 9 & 5 & 4 & 0.823 & 0.8232 & 0.9489 \\
\hline CPR & 9 & 3 & 6 & 0.896 & 0.6256 & 0.8696 \\
\hline EGR & 9 & 4 & 5 & 0.925 & 0.3112 & 0.6480 \\
\hline AGR & 9 & 5 & 4 & 0.778 & 0.3299 & 0.6259 \\
\hline LBL & 9 & 4 & 5 & 0.640 & 0.5680 & 0.8590 \\
\hline Total & $\mathbf{8 1}$ & $\mathbf{3 8}$ & $\mathbf{4 3}$ & & & \\
\hline Sourcennyyynnn
\end{tabular}

Source: Pilot survey data $(\mathrm{n}=36)$

Note: AVE - Average Variance Extracted; CR - Construct Reliability

Finally, we used the values of the Incentive Index derived for each incentive to derive the MTMM matrix, which represents the correlation between: (i) the value of the Incentive Index derived for each incentive, and (ii) the value of the corresponding single-item Validation Items. In the MTMM matrix, the values representing the leading diagonal are significantly greater than the correlation coefficients for non-corresponding scales off of the leading diagonal (Table 2). This proves that the incentive indices derived through MISS techniques were valid measures of the respective incentives as they passed the test for both Convergent and Discriminant Validity. At the end of this three-stage CFA 
process (i.e., Scale Reliability, Unidimensionality and Construct Validity), we selected these 43 statements to be included in the final questionnaire.

\subsection{Main Survey - Data Collection and Analysis}

We repeated the procedures adopted in the Pilot Survey in the Main Survey carried out from January to September 2009 to collect data from 325 firms.

We estimated the Measurement Model (MM) constructed through the Analysis of Moment Structures (AMOS) [version 16] software (see Figure 02) using the MLE, where we considered the recommendations of Hair et al., (1998) to assess the validity of MM in terms of both Model Fit and Construct Validity. The summary of goodness-of-fit measures obtained highlights that the overall model $\mathrm{X}^{2}$ is 1901.67 with 824 degrees of freedom (df). The probability value associated with this result is 0.000 and the model is significant at $\rho=0.001$. Also the ratio of $\mathrm{X}^{2}$ /df was 2.308 (i.e., 1901.67/824), which was below the accepted cut-off value of $<3.00$. An analysis of the other selected goodness-of-fit measures shows reliable model fit (Table 3). As a minimum requirement, the estimates of Factor Loadings (given as Regression Weights in AMOS) should be statistically significant to support Convergent Validity. Hair et al., (2006) recommend that the standardised Regression Weights should be 0.5 or higher, ideally 0.7 or higher. The outcome shows that all loadings of the estimated model were significant while 31 out of 43 statements considered had standardized Regression Weights above the 0.7 cutoff, with only 5 statements (i.e., CPR2, EGR2, EGR3, AGR4, and LBL3) were having standardized loadings below 0.5.

Next, we estimated the Average Variance Extracted (AVE) and Construct Reliabilities (CR). We report the results in Table 1. The CR estimates for all but two incentives (EGR and AGR) are above the ideal 0.7 cutoff but even these two incentives are above the generally acceptable 0.6 cutoff. Only three incentives of the AVE (CPR, EGR and AGR) are below the 0.5 cutoff. This has resonance with the low Regression Weights obtained for indicators of these incentives. For all nine incentives as a whole, the indicators were sufficient in terms of how the $\mathrm{MM}$ was specified. The satisfaction of conditions for all the Regression Weights, CR, and AVE support the Convergent Validity of the MM to a reasonable extent. However, there is a need to consider whether the indicators have low loadings which need to be pruned.

When considering Discriminant Validity, Table 4 shows that 27 out of the 36 inter-construct combinations satisfied the criterion and only 9 inter-construct correlations (highlighted) exceed the AVEs of either of the Latent Constructs (Hair et al., 1998). Apart from the analysis through AMOS, the MTMM matrix derived for this stage, which utilized the scores provided by 325 firms to the 9 single-item Validation Items and the Incentive Index derived for the corresponding 9 incentives, also show that the values in the leading diagonal 
(highlighted) are not only significantly greater than the correlation coefficients for non-corresponding scales off of the leading diagonal (Table 5). In fact, the corresponding values in the leading diagonals reported in Table 5 are greater than that obtained in the Pilot Survey (Table 2) proving that the selected indicators perform quite satisfactorily with the large sample. At the end of this process, we considered all the statements included in the questionnaire to derive the Incentive Index of each incentive since those minute deviations from the accepted norms in certain statements cannot have a sizeable impact on the overall result.

\section{Results and Discussions}

\subsection{Characteristics of Firms in the Sample}

We collected data from 325 firms categorized under five types on the basis of their produce and further categorized taking into account their value of annual sales. Interestingly, the majority of firms producing essential oils (64.4 percent) and other processed products (67.1 percent) were either Small or Very Small. On the other hand, the firms engaged in producing coconut products (48.3 percent) and non-alcoholic beverages (65.2 percent) were either Large or Very Large (Table 6). Nearly 40 percent of firms were involved in international markets (i.e., exporting). Further, about 50.5 and 46.5 percent of firms traded with wholesalers and direct customers (see Figure 03). Nevertheless, a significant variation was observed with regard to size of the firm and the 
Table 2: Multi-Trait Multi-Item Matrix for the Pilot Survey

\begin{tabular}{|c|c|c|c|c|c|c|c|c|c|c|}
\hline & \multicolumn{10}{|c|}{ Validation Item } \\
\hline \multirow{10}{*}{ 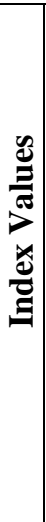 } & & $\mathbf{V}_{1}$ & $\mathbf{V}_{2}$ & $\mathbf{V}_{3}$ & $\mathbf{V}_{4}$ & $\mathbf{V}_{5}$ & $\mathrm{~V}_{6}$ & $\mathbf{V}_{7}$ & $\mathrm{~V}_{8}$ & $\mathrm{~V}_{9}$ \\
\hline & CST & $-.934(* *)$ & $.438(* *)$ & $.644(*)$ & -.079 & $.211\left(^{*}\right)$ & $.325(*)$ & -.187 & $.099(*)$ & $.577(*)$ \\
\hline & TCE & $-.643(* *)$ & $.769(* *)$ & $.794(* *)$ & $-.213(*)$ & $.452(*)$ & $.577(* *)$ & $.232(*)$ & $.491(*)$ & $.222(*)$ \\
\hline & HRE & $-.762(* *)$ & $.743(* *)$ & $.903(* *)$ & $-.297\left(^{*}\right)$ & $.571(* *)$ & $.577(* *)$ & -.039 & .401 & .204 \\
\hline & SLR & $-.721(*)$ & $.511(* *)$ & $.562(*)$ & $-.301(*)$ & $.467(* *)$ & $.652(* *)$ & -.328 & .156 & $.447(*)$ \\
\hline & CPR & $-.422(*)$ & $.691(* *)$ & $.551(*)$ & $-.623(*)$ & $.910(* *)$ & $.439(*)$ & $.596(* *)$ & $.559(*)$ & $.502\left(^{*}\right)$ \\
\hline & REP & $-.688(* *)$ & $.634(* *)$ & $.710(* *)$ & $-.581(* *)$ & $.721(* *)$ & $.729(* *)$ & $-.478(*)$ & .401 & $.662(* *)$ \\
\hline & EGR & $-.211(*)$ & $.483(*)$ & $.467(*)$ & $-.344(*)$ & $.590(* *)$ & $.298(*)$ & $.884(* *)$ & $.725(* *)$ & $.491(*)$ \\
\hline & AGR & $-.578(* *)$ & $.775(* *)$ & $.751(* *)$ & $-.461(*)$ & $.872(* *)$ & $.455(*)$ & $.782(* *)$ & $.732(* *)$ & $.509(*)$ \\
\hline & LBL & $-.453(*)$ & $.629(* *)$ & $.565(* *)$ & $-.678(*)$ & $.559\left(^{*}\right)$ & $.601(* *)$ & $.672(*)$ & $.572(*)$ & $.728(* *)$ \\
\hline
\end{tabular}

Note: $\mathrm{V}=$ Validation item representing corresponding incentives

${ }^{* *}$ Correlation is significant at the 0.01 level (2-tailed).

* Correlation is significant at the 0.05 level (2-tailed).

${ }^{\text {a }}$ Cannot be computed because at least one of the variables is constant. 
Table 3: Measurement Model Fit Indices

\begin{tabular}{|l|c|c|}
\hline $\begin{array}{l}\text { Goodness-of-fit } \\
\text { Measures }\end{array}$ & Estimates & $\begin{array}{c}\text { Cutoff values based on model } \\
\text { characteristics }\end{array}$ \\
\hline Chi-square $\left(\mathrm{X}^{2}\right)$ & 1901.667 & \\
\hline Degrees of freedom & 824 & Significant p-values can be expected \\
\hline Probability level & 0.000 & $<3$ \\
\hline $\mathrm{X}^{2} /$ d. f. Ratio & 2.308 & $>0.90$ \\
\hline CFI & 0.921 & $>0.90$ \\
\hline TLI & 0.914 & $<0.07$ with CFI of 0.90 or higher \\
\hline RMSEA & 0.064 & R \\
\hline
\end{tabular}

Note: CFI - Comparative Fit Index; TLI - Tucker Lewis Index; RMSEA - Root Mean Square of Approximation

Table 4: Estimates of Squared Correlations Compared with Variance Extracted Estimates to Establish Discriminant Validity

\begin{tabular}{|c|c|c|c|c|c|c|c|c|c|}
\hline CST & & & & & & & & & \\
\hline TCE & 0.91 & & & & & & & & \\
\hline HRE & 0.81 & 0.81 & & & & & & & \\
\hline SLR & 0.68 & 0.70 & 0.79 & & & & & & \\
\hline CPR & 0.77 & 0.94 & 0.75 & 0.70 & & & & & \\
\hline REP & 0.84 & 0.81 & 0.74 & 0.61 & 0.73 & & & & \\
\hline EGR & 0.46 & 0.39 & 0.57 & 0.68 & 0.47 & 0.35 & & & \\
\hline AGR & 0.43 & 0.34 & 0.42 & 0.45 & 0.36 & 0.35 & 0.45 & & \\
\hline \multirow[t]{2}{*}{ LBL } & 0.79 & 0.71 & 0.67 & 0.59 & 0.68 & 0.61 & 0.33 & 0.38 & \\
\hline & CST & TCE & HRE & SLR & CPR & REP & EGR & AGR & LBL \\
\hline$A V E$ & 0.87 & 0.86 & 0.66 & 0.63 & 0.82 & 0.46 & 0.31 & 0.33 & 0.57 \\
\hline
\end{tabular}


Table 5: Multi-Trait Multi-Item Matrix for the Main Survey 
type of customer they dealt with. Almost 71 and 59 percent of Very Large and Large firms, respectively, exported their products while only 23 and 1.3 percent of Small and Very Small firms did so.

Table 6: Statistics of Sample from Main Survey

\begin{tabular}{|l|c|c|}
\hline Basis of Categorization & Category & No. of Firms \\
\hline \multirow{4}{*}{ Type of Firm } & COP & $31(9.5 \%)$ \\
\cline { 2 - 3 } & ESO & $59(18.2 \%)$ \\
\cline { 2 - 3 } & NAB & $72(22.2 \%)$ \\
\cline { 2 - 3 } & OPP & $70(21.5 \%)$ \\
\cline { 2 - 3 } & PFV & $93(28.1 \%)$ \\
\hline \multirow{4}{*}{ Scale of Operation } & Very Small & $80(24.6 \%)$ \\
\cline { 2 - 3 } & Small & $70(21.5 \%)$ \\
\cline { 2 - 3 } & Medium & $50(15.4 \%)$ \\
\cline { 2 - 3 } & Large & $56(17.2 \%)$ \\
\cline { 2 - 3 } & Very Large & $69(21.2 \%)$ \\
\hline \multicolumn{2}{|c}{ Total } & \\
\hline
\end{tabular}

Note: AVE - COP - Coconut Products; ESO - Essential Oils; NAB - NonAlcoholic Beverages; OPP - Other Processed Products; PFV - Processed Fruits and Vegetables; Very Small : < Rs. 100,000); Small : Rs. 100,000 - 500,000); Medium : Rs. 500,000 - 1,000,000); Large : Rs. 1,000,000 - 5,000,000); Very Large : > Rs. 5,000,000

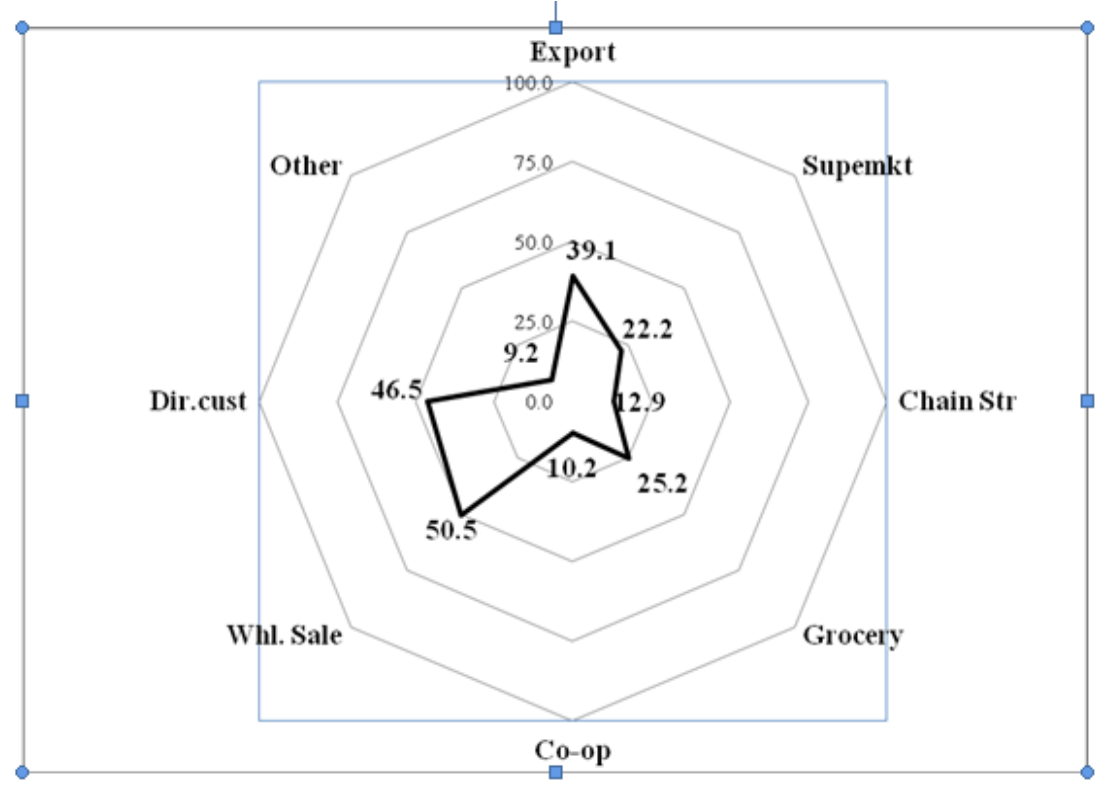

Figure 3: Type of Customers of Firms 


\subsection{Types of SWMPs Adopted by Firms and the Strength of Individual Incentives}

Figure 04 illustrates that "Composting" (31.4 percent), "3R system" (24 percent) and "Good Manufacturing Practices" (24 percent) were popular as measures to control solid waste generated in the firm as compared to "Bio Gas Unit" (4 percent) and "ISO 14000 series" (4.6 percent). Only 17 (5.3 percent) firms have more than 5 SWMPs in place (Figure 05). The number of SWMPs adopted by a firm varied to a great extent vis-à-vis the type of the firm and its size. Firms that produced non-alcoholic beverages (NAB) and processed fruits and vegetables (PFV) tended to adopt a higher number of SWMPs in comparison with those that processed essential oils (ESO) and coconut products (COP). With regard to firm size, large firms, not surprisingly, tended to adopt a higher number of SWMPs. For example, nearly 29 percent of Very Large firms adopted more than 4 such practices in the firm compared to 71.3 percent of Very Small firms who did not adopt a single practice.

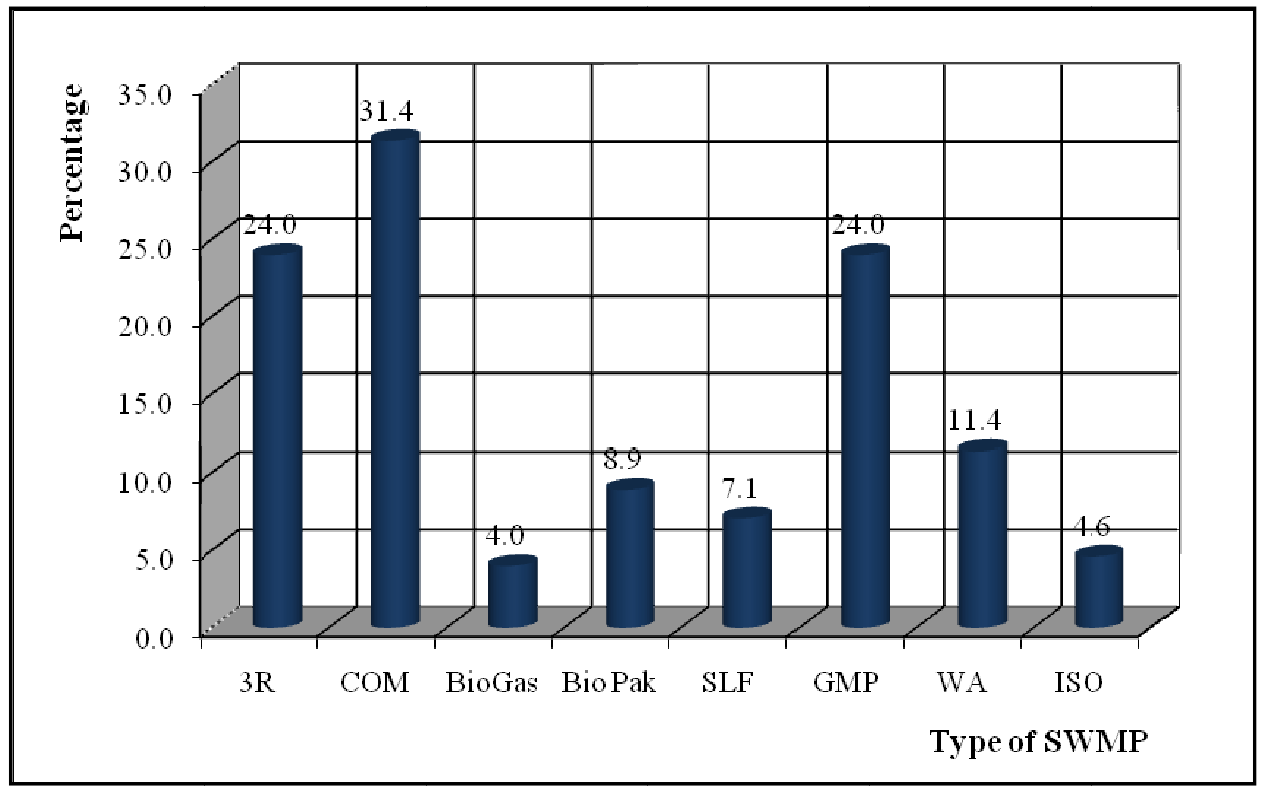

Figure 4: Different Types of SWMPs Adopted by Firms 


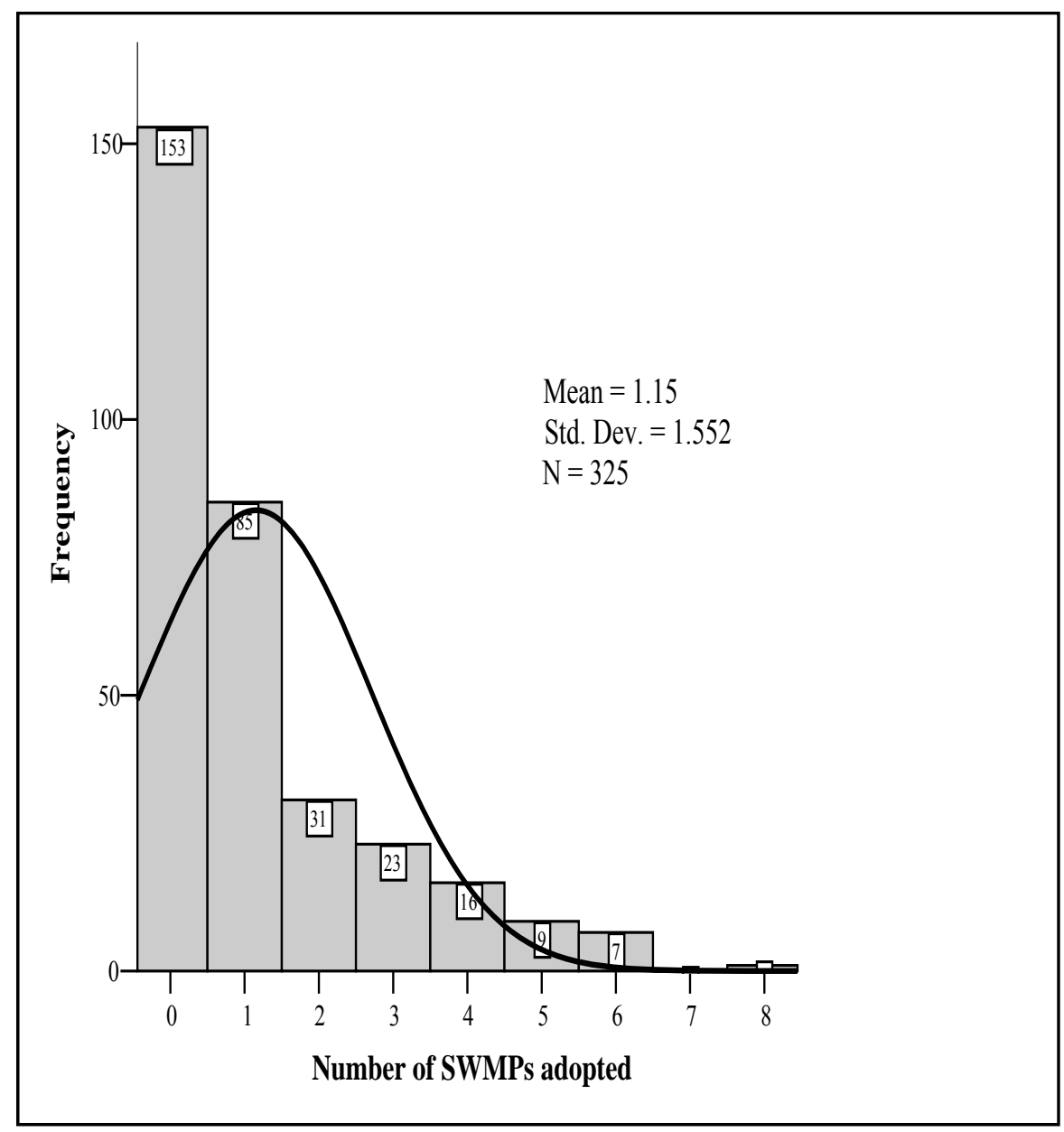

Figure 5: Total Number of Different SWMPs Adopted by Firms

After estimation of the hypothesized MM, it becomes possible to derive an Incentive Index for each economic incentive and complete the development of estimable variables for each of the latent constructs. We have used the index to evaluate the impact of each incentive on firm decision to adopt SWMPs. Figure 06 illustrates the values of the Mean Incentive Index (MII) for each of the 9 incentives considered in this analysis vis-à-vis the number of SWMPs adopted. It shows that for firms either without or with a small number (i.e., one or two) SWMPs, the value of the MII of most market-based incentives were either negative (e.g., CST, HRE, TCE, SLR, REP) or only slightly positive (e.g., CPR). Further, the values of the MII of regulatory and liability incentives were positive irrespective of the number of SWMPs in place. In fact, it tells us that as the value of the MII of all these incentives increases, firms tend to adopt a higher number of SWMPs. The results also suggest that the magnitudes of the Incentive 
Index, which reflects the relative strength of an incentive, is perceived by the majority of the firms, on average, between -0.5 to 0.5 indicating that most firms, especially the Very Small to Medium scale firms, did not consider these incentives as very important in their decision to adopt SWMPs. It shows that the firms' level of adoption of these SWMPs were relatively low with mean of 1.2 practices in place out of the 8 such practices recommended by the Ministry of Environment.

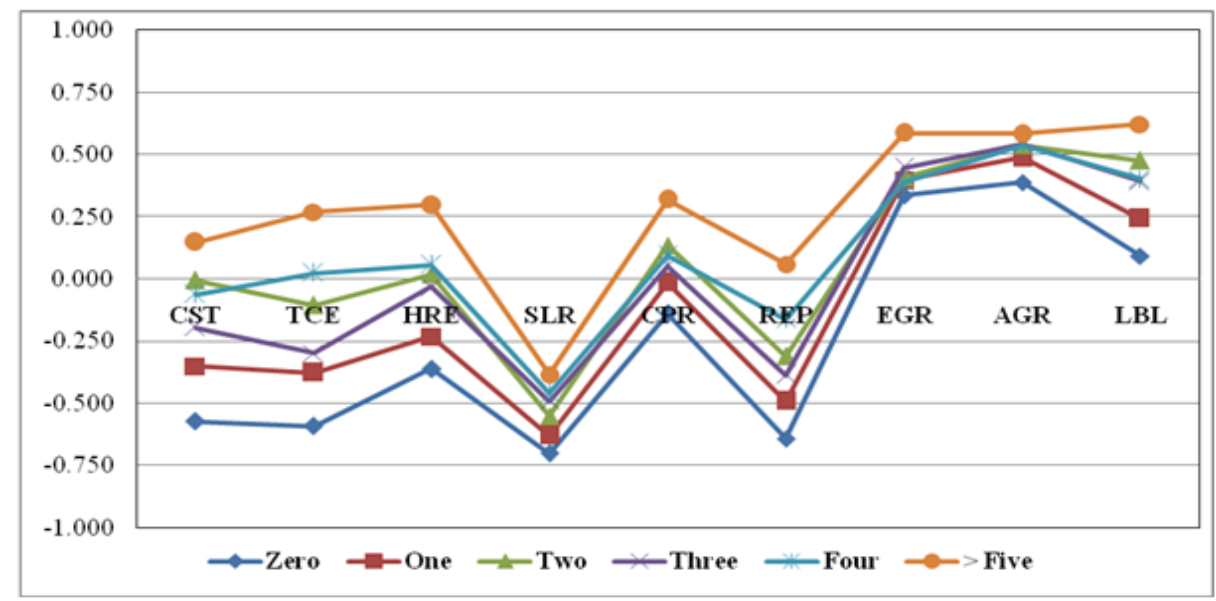

Figure 6: Number of SWMPs Adopted by a Firm and Value of Incentive Index

\section{Conclusions and Future Studies}

This study creates numerous advancements in social science research in the areas of agricultural economics, environmental economics and agricultural policy development. Considerable groundbreaking work has been done in adopting from the opus of behavioral economics, psychology, more specifically psychometrics (Nunally, 1978), organizational studies (Hughes et al., 1986) and marketing and adapting to the context of an economics research project. The key issue for researchers working in the study of firm behavior is trying to "predict", "map" or "quantify" perceptual dimensions that antecede and/or moderate managerial decision making; in other words 'make sense of what is happening inside the mindsets of firms' decision makers'. With the focus of this study being on economic incentives, we were faced with a similar predicament and needed: (1) an objective, (2) scientific and (3) robust way of studying and quantifying the relationship between these incentives and firm decisions on implementing SWMPs such as ISO 14001 in their plants (Henson and Traill, 2000; JayasingheMudalige and Henson, 2006). Through this study the methods of SEM thorough AMOS and index derivation for perceptual quantification have been refined and 
are now open to other researchers and scientists to work on further. The estimable variables developed through this methodological procedure can now be used in modeling the impact of these incentives on firm environmentally responsive behavior.

\section{Acknowledgement}

We fully acknowledge the financial and technical support provided by the South Asian Network for Development and Environmental Economics (SANDEE). The support extended by the owners/managers of firms participated to this study and those who supported to obtain contacts of these firms.

\section{References}

1. Buchanan, J. M., (1969). Cost and choice: an inquiry in economic theory, Chicago: Markham. Publishing Co.

2. Caswell, J. A., Bredahl, M. E. and Hooker, N. H. (1998). How quality management meta-systems are affecting food industry. Review of Agricultural Economics, 20, 547-557.

3. Campbell, D. T. and D. W. Fiske (1959). Convergent and discriminant validation by the multitrait multimethod matrix, Psychological Bulletin 56: 81-105.

4. Cronbach, L. J. (1951). Coefficient alpha and the internal structure of tests, Psychometrica 16(3): 297-333.

5. De Vellis, R. F. (1991). Scale Development: Theory and Applications, Sage Publications: Newbury Park.

6. Fornell, C. and Bookstein, F. L. (1982). Two structural equation models: LISREL and PLS applied to consumer exit-voice theory. Journal of Marketing Research, 19(4), 440-453.

7. Fornell, C. and Larker, D. F. (1981). Structural equation models with unobservable variable and measurement error: algebra and statistics. Journal of Marketing Research, 18(3), 382-388.

8. Garver, M. S. and Mentzer J.T. (1999). Logistics research methods: employing structural equation modeling to test for construct validity. Journal of Business Logistics, 20(1), 33-57.

9. Hair, J. F., Anderson, R. E., Tatham, R. L. and Black, W. C. (1998). Multivariate data analysis. (5th ed.). Prentice-Hall, New Jersey. 
10. Henson, S. and Traill, B. (2000). Measuring perceived performance of the food system and consumer food-related welfare. Journal of Agricultural Economics, 51(3), 388 - 404.

11. Hoe, S. L. (2008). Issues and procedures in adopting structural equation modeling technique. Journal of Applied Quantitative Methods, 3(1), 76-83.

12. Hughes, M. A., Price, R. L. and Marrs, D. W. (1986). Linking theory construction and theory testing: models with multiple indicators of latent variables. Academy of Management Review, 11(1), 128-144.

13. Jayasinghe-Mudalige, U. K. and Henson, S. (2006). Economic incentives for firms to implement enhanced food safety controls: case of the Canadian red meat and poultry processing sector. Review of Agricultural Economics, 28(4), 494-514.

14. Jayasinghe-Mudalige, U. K. and Henson, S. (2007). Identifying economic incentives for Canadian red meat and poultry processing enterprises to adopt enhanced food safety controls. Food Control, 18(1), 1363-1371.

15. Jöreskog, K. and Sörbom, D. (2001) Lisrel 8: user's reference guide. (2nd ed.). Lincolnwood: Scientific Software International Inc.

16. Nakamura, M., Takahashi, T. and Vertinsky, I. (2001). Why Japanese firms choose to certify: a study of managerial responses to environmental issues. Journal of Environmental Economics and Management, 42(1), 23-52.

17. Nunnally, J. C. (1978) Psychometric Theory. New York: Mc-Graw Hill.

18. Oppenheim, A. N. (1992) Questionnaire Design, Interviewing and Attitude Measurement. Pinter, London.

19. Segerson, K. (1999). Mandatory versus voluntary approaches to food safety. Agribusiness, 15(1), 53-70.

20. Shavell, S. (1987). Economic analysis of accident law. Cambridge: Harvard University Press.

21. Zechmeister, J. S., Zechmeister, E. B. and Shaughnessy, J. J. (2009). Essentials of Research Methods in Psychology. New Delhi: Tata McGrawHill Education.

22. Zikmund, W. G. (2003). Business Research Methods. 7th edition. New Delhi: Cengage Learning. 
